\title{
Numerical Investigation of Startup Instabilities in Parallel-Channel Natural Circulation Boiling Systems
}

\author{
S. P. Lakshmanan and Manmohan Pandey \\ Department of Mechanical Engineering, Indian Institute of Technology Guwahati, Guwahati, Assam 781039, India \\ Correspondence should be addressed to Manmohan Pandey, manmohan@iitg.ernet.in
}

Received 11 November 2009; Revised 5 April 2010; Accepted 13 April 2010

Academic Editor: Jose Reyes

Copyright (C) 2010 S. P. Lakshmanan and M. Pandey. This is an open access article distributed under the Creative Commons Attribution License, which permits unrestricted use, distribution, and reproduction in any medium, provided the original work is properly cited.

\begin{abstract}
The behaviour of a parallel-channel natural circulation boiling water reactor under a low-pressure low-power startup condition has been studied numerically (using RELAP5) and compared with its scaled model. The parallel-channel RELAP5 model is an extension of a single-channel model developed and validated with experimental results. Existence of in-phase and out-of-phase flashing instabilities in the parallel-channel systems is investigated through simulations under equal and unequal power boundary conditions in the channels. The effect of flow resistance on Type-I oscillations is explored. For nonidentical condition in the channels, the flow fluctuations in the parallel-channel systems are found to be out-of-phase.
\end{abstract}

\section{Introduction}

A proper understanding of the system behavior and other important parameters during the startup of a natural circulation boiling water reactor (NCBWR) is of primary importance in thermal hydraulic safety analysis. At low pressures, a natural circulation loop typically has three operation ranges: single-phase stable region, two-phase unstable region, and two-phase stable region. During the startup, the system undergoes a transition from stable single-phase region to a stable two-phase operating region. While in the process of transition, the system has to cross through an unstable twophase region, where the system flow sets up to an oscillatory mode mainly induced by the phenomena of flashing in the riser section (i.e., steam production in adiabatic conditions) and geysering in the heated channel. Fundamental studies in the area of geysering instability have been conducted by Aritomi et al. [1] and $\mathrm{Wu}$ et al. [2]. A detailed study on flashing-induced instability and their difference from other types of instabilities has been done and reported by Manera and van der Hagen [3] and Furuya et al. [4] through their experiments conducted on CIRCUS and SIRIUS-N facilities, respectively.
Researchers in the recent past have reported and discussed various instabilities that occur in a natural circulation boiling system at low-pressure low-power startup conditions. The findings so far reported are results of research focused on the development of single-channel vessel type NCBWRs like ESBWR from GE and so forth. The nature of transients is mostly explained through single-channel studies. Very few investigations have been done to study the low-pressure transients that could occur in a parallel channel natural circulation boiling system. An experimental study using a double-channel natural circulation loop was carried out, and the transport mechanism of various types of instability under startup conditions was discussed [5]. In-phase and out-of-phase flow oscillations were reported. Out-of-phase flow oscillations were reported through an experimental observation [6] as cited in [7]. Through a numerical study, the nonlinear dynamics and stability boundary of a double-channel natural circulation boiling loop analyzed [7]. The motivation behind the above-mentioned doublechannel works was mainly to simulate the flow inside the parallel tubes of the reactor core. The current study assumes importance in simulating a multichannel pressure tube type reactor, having tubes with riser section (adiabatic) running up to $25 \mathrm{~m}$ height. Due to the strong variation of saturation 


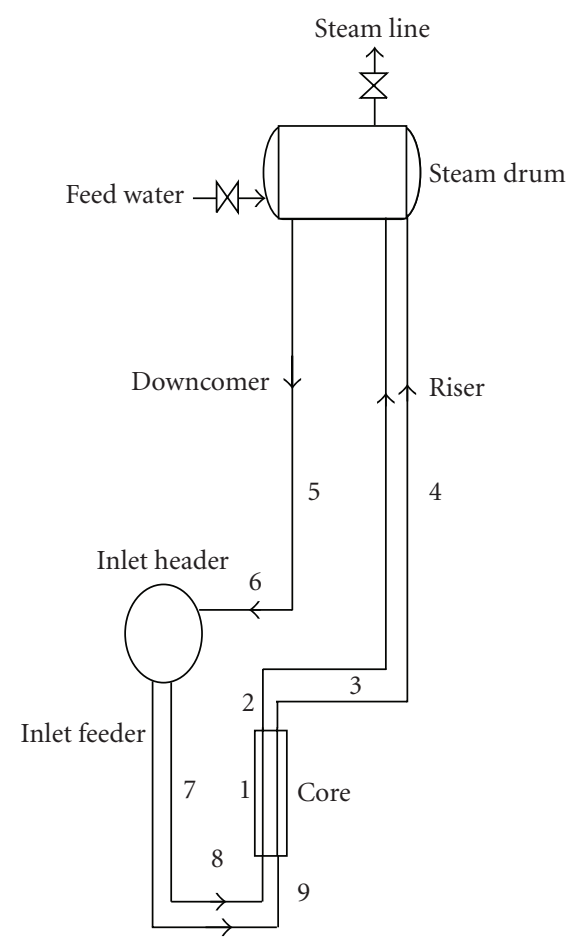

Figure 1: Schematic and major dimensions of the PHT loop.

temperature along the length, flashing can occur in the adiabatic section during the startup of the reactor.

Numerical simulation of startup transients would be helpful in predicting instabilities and for devising appropriate startup methods. For accurate modeling of twophase flow systems, a two-fluid model is used, where the two phases are treated as two coexisting continua for which mass, momentum, and energy balances are set up separately. This type of model is implemented in some of the codes (e.g., RELAP5, TRAC, and MONA) and allows considering thermal nonequilibrium and slip between the phases. Startup transient simulations for GE SBWR have been done using RAMONA-4B code [9]. No oscillations, especially geysering and flashing type instability as observed in the various test facilities, were found in these simulations because RAMONA-4B code calculates thermodynamic properties at the system average pressure. RELAP5/MOD3 code is employed not only to simulate a natural circulation experiment in IIST facility, but also to investigate the event of decay heat removal in a pressurized water reactor [10]. The calculated results are found to be in good agreement with the experimental single-phase natural circulation data. Later, the RELAP5 code was used to predict the transients under low-pressure low-power natural circulation boiling system and the results are found to closely match with the experimental observations of a test facility $[8,11]$. In the present work, numerical simulations of transients at low-pressure and low-power conditions in double-channel natural circulation boiling systems are performed using RELAP5/SCDAPSIM/MOD3.4 [12] code.
TABLe 1: Major dimensions for the links shown on Figure 1.

\begin{tabular}{lccc}
\hline Link no. & $\begin{array}{c}\text { Single channel flow } \\
\text { area }\left(\mathrm{m}^{2}\right)\end{array}$ & Length $(\mathrm{m})$ & $\begin{array}{c}\text { Change in } \\
\text { elevation }(\mathrm{m})\end{array}$ \\
\hline 1 & 0.00485 & 3.5 & 3.5 \\
2 & 0.00325 & 3.8 & 3.8 \\
3 & 0.00325 & 23.6 & 0.0 \\
4 & 0.0017 & 25.5 & 25.5 \\
5 & 0.00231 & 26.8 & -26.8 \\
6 & 0.00231 & 6.33 & 0.0 \\
7 & 0.00742 & 10.62 & -10.62 \\
8 & 0.00742 & 7.11 & 0.0 \\
9 & 0.00273 & 4.89 & 4.89 \\
\hline
\end{tabular}

The objective here is to investigate the existence of inphase and out-of-phase Type-I instabilities that could occur during startup of parallel-channel systems. The tool used in the current numerical work is RELAP5/SCDAP/MOD3.4 code, and the details of the numerical model are discussed in Section 3. The observations under similar and different boundary conditions (power and flow restriction) in the two channels are discussed along with a comparison in flow behaviour predicted in a model and its prototype, in the context of in-phase and out-phase oscillations (Section 4).

\section{Description of Parallel-Channel Systems}

It is intended to study the behaviour of a parallel-channel reactor under a low-pressure low-power startup condition and also to compare the characteristics with its scaled model (a test facility). The boiling water reactor (BWR) under study is a vertical, natural circulation cooled, pressure tube type reactor [13]. The components of the primary heat transport (PHT) system and their major dimensions are shown in Figure 1 and Table 1, respectively. The PHT loop consists of 452 coolant channels (core and riser) connected to 4 steam drums. For the current study, a numerical model comprising a system of two identical parallel loops, each consisting of a core, a riser and a common downcomer, is considered. Each of the loops represents 56 channels, and both loops together represent one-fourth of the total channels of the prototype. All the 56 channels are averaged into a single equivalent channel assuming that all the channels get the same power. The flow area of a single equivalent channel is equal to the flow area of 56 channels. The hydraulic diameter of the equivalent channel is equal to the hydraulic diameter of a single channel in the prototype.

The details of the scaled system, considered for the study, are from a natural circulation test facility (NCTF) [14]. The test facility is a scaled model designed to simulate a pressure tube type reactor driven by natural circulation. The length scale used in the test facility is $1 / 4$ and the time scale is accelerated by a factor of 2 . The model-to-prototype scaling ratios are given in Table 2 . The schematic and major dimensions of a single loop of the test facility are also reported in [8]. 


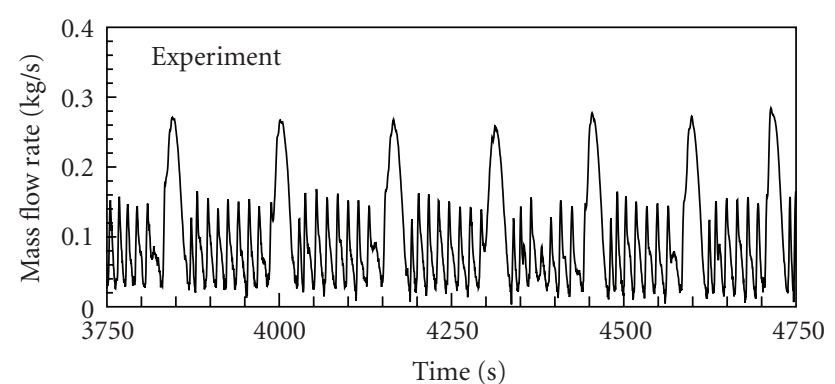

(a)

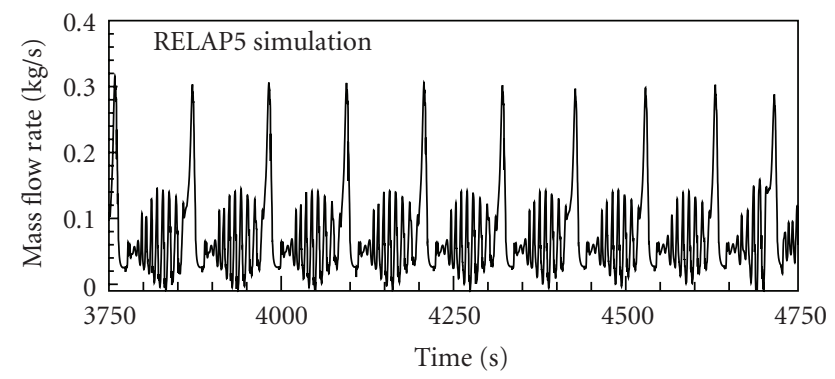

(b)

Figure 2: Mass flow rate observed during experiment and RELAP5 simulation [8].

TABLe 2: Model-to-prototype scaling ratios [8].

\begin{tabular}{lc}
\hline Parameter & Model-to-Prototype Ratio \\
\hline Elevations & $1 / 4$ \\
Power & $1 / 2702.6$ \\
Number of fuel rods & $1 / 663$ \\
Linear heating rate & $2 / 1$ \\
Core hydraulic diameter & $1 / 1$ \\
Cross sectional area & $1 / 1351.3$ \\
Feed flow & $1 / 2702.6$ \\
Length of links & $1 / 4$ \\
Number of risers/feeders & $1 / 51$ \\
Number of downcomers & $1 / 4$ \\
\hline
\end{tabular}

\section{Numerical Model}

In a previous work by Lakshmanan et al. [8], RELAP5 models were developed for the natural circulation loop of a test facility and the prototype. The RELAP5 model of the test facility was validated for its transient predictions under low-pressure startup conditions with the help of experimental observations (Figure 2). The details of the test facility, model development, validation, and verification were reported in [8], and the same will not be repeated here. In the current study numerical models for the parallelchannel systems described in Section 2 were developed with RELAP5/SCDAPSIM/MOD3.4. This parallel-channel RELAP5 model is an extension of the previous single-channel model. Details of the RELAP5 nodalization scheme and the simulation procedure followed for predicting the startup

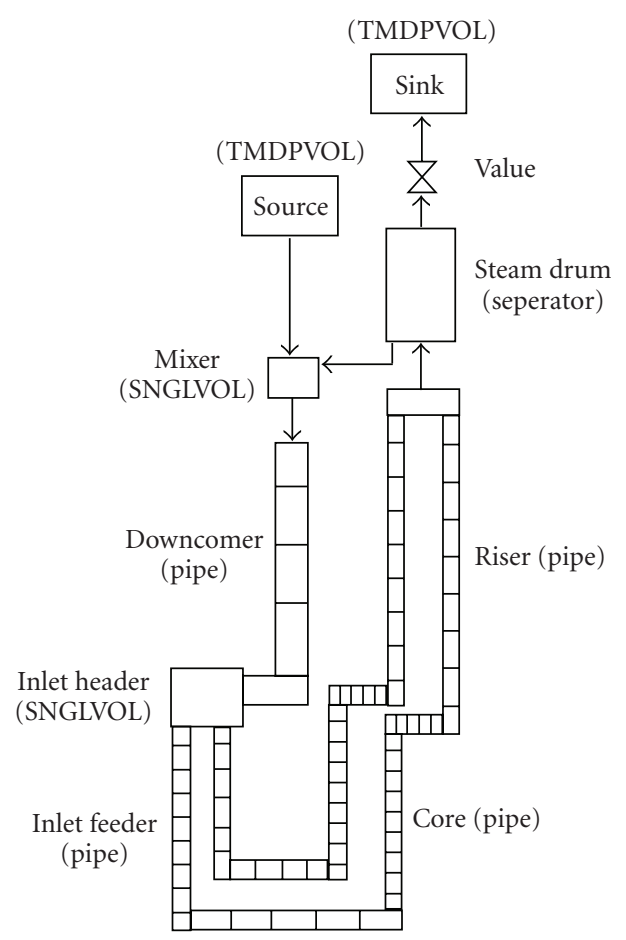

FIgURE 3: RELAP5 nodalization scheme for PHT loop.

transients in parallel-channel systems are discussed in this section.

3.1. Nodalization Scheme for RELAP5 Simulation. The PHT loop described in Section 2 is nodalized in RELAP5 as shown in Figure 3. The core and the riser sections were modeled as pipe components, each divided into 32 and 36 control volumes for NCBWR and 8 and 16 control volumes for the test facility, respectively. The choice of nodal size is based on a previous work [8], where the nodal sensitivity study was carried out for a single-channel model. A simple separator model is used for modeling the steam drum, and the downcomer is modeled as a pipe component. In order to facilitate the connection of both the parallel riser pipes to the steam drum, a branch component having an area equal to the sum of those of the riser pipes is used. The lower part of the steam drum is modeled as a mixer using a single volume component. A trip valve is used for modeling the steam control valve. A time-dependent junction between the source and the mixer facilitates the control of feed water supply, which is equal to the mass flow rate of steam exit from the drum to sink. The heater elements in the core are modeled as heat structures. The length of each axial heat structure node is consistent with the length of the hydrodynamic component. To account for the effect of thermal capacitance, heat structures are applied for all the components of the loop.

3.2. RELAP5 Simulation Procedure. Simulation for startup transients was done using RELAP5. The input deck was developed that includes the modeling of all major components of the PHT loop. The initial and boundary conditions 


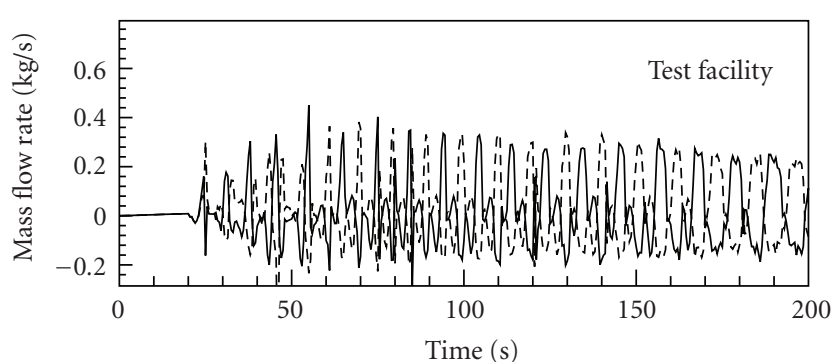

(a)

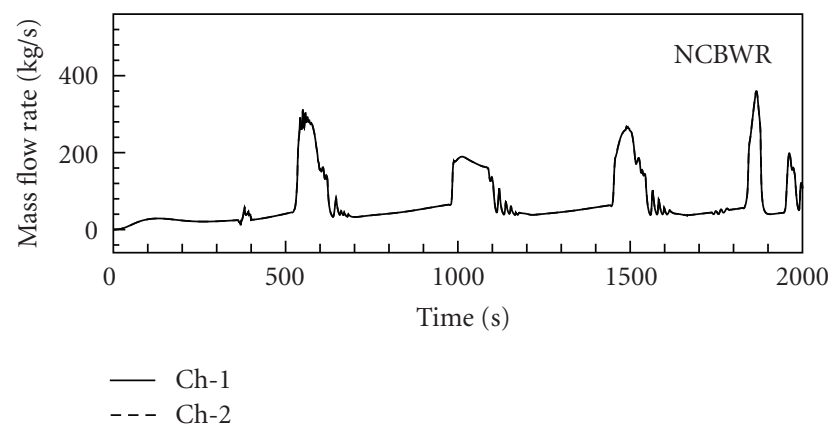

(b)

FIgURe 4: Prediction for double-channel power input with equal power.

employed are as follows. Before startup, the steam drum pressure is kept at a very low pressure $(55 \mathrm{kPa})$, and the coolant in the entire loop is kept at an initial temperature of $80^{\circ} \mathrm{C}$ (which is very close to the saturation temperature at $55 \mathrm{kPa}$ ). The initial flow condition is set to zero, and the power input is through a general power table. The steam control valve remains closed during the simulation, keeping no contact between the system and the sink. Simulations are done for different initial and boundary conditions. The mass flow rate, pressure, and temperature reported in the subsequent sections shall be presumed as predicted at the inlet of the core, if not otherwise mentioned.

\section{Results and Discussion}

The existence of in-phase and out-of-phase flashing instabilities during the startup of parallel-channel systems was investigated. Simulations were carried out under equal and unequal initial flow and power boundary conditions between the channels. The behavior of flow oscillations for different values of flow resistance between the two channels is studied. The nature of flow transients under double-channel power input conditions is investigated. Cases with equal and unequal power boundary conditions between channels are studied as discussed in this section.

4.1. Channels with Equal Power. Simulations were carried out using a constant power (5\% of full power) with the initial conditions of the reactor being set as mentioned in Section 3.2. Figure 4 shows the flow behavior during startup simulations of both model and prototype under equal power boundary conditions. In model, the flow is characterized by pulses which are out-of-phase between Channel-1 and Channel-2, and flow reversal is predicted in both the channels with equal magnitude (Figure 4(a)). It can be inferred that the flow in both the channels is in-phase, until it reaches the peak of the first pulse and from there on develops a phase difference. Earlier, the persistence of out-of-phase oscillations even under equal power condition between channels was reported through experimental studies by Subki et al. [5] and Chen et al. [15]. Similar observation is reported by Jain et al. [16] in their experiments conducted in a natural circulation parallel-channel model; they also characterized such oscillations as mixed mode oscillation. Figure 4(b) shows that the flow in NCBWR is characterized by flashing pulses which are in-phase between Channel1 and Channel-2, with no flow reversal. Hence, there is a difference between the nature of flow oscillations predicted in model and prototype, in the context of in-phase and out-of-phase behaviour. In general, the major cause for the different nature of startup oscillations in the model and prototype can be attributed to the reduced height of the test facility considered. Hence, the choice of major scaling parameters (height, pressure, etc.) for a natural circulation system is likely to be complex, especially when the facility has to simulate the exact transient phenomenon occurring right from startup to operating conditions.

4.2. Channels with Unequal Power. Simulations were carried out for a power difference of $10 \%$ and $50 \%$ between channels. The observations made under such different power boundary conditions in model and NCBWR are presented in this section.

Figure 5 shows the flow behavior, predicted when Channel-1 of model is supplied with $4 \mathrm{~kW}$ and channel-2 with $3.6 \mathrm{~kW}$, that is, $10 \%$ power difference between channels. The flow oscillations in the channels are found to be in outof-phase, with the flow pulses in Channel-2 lagging behind. Figure 6 shows the flow behavior, predicted when Channel-1 of the model is supplied with $4 \mathrm{~kW}$ and channel- 2 with $2 \mathrm{~kW}$, that is, $50 \%$ power difference. Although the usual trend of out-of-phase behaviour is predicted during the initial flow oscillations, it should be noted that, after the occurrence of first flashing pulse (at 225s) in channel-1, the flow in Channel-2 gets reversed and remains to flow in the negative direction for a longer period (until $1500 \mathrm{~s}$ ). This is due to the fact that the rate of increase in temperature of liquid in Channel-2 is comparatively low, causing a delay in vapor generation. In addition to that, the liquid in Channel-2 is not allowed to gain enough heat for vapor generation as there is flow reversal caused by the oscillations in Channel-1.

Figure 7 shows the flow behavior predicted in NCBWR, when Channel-1 is supplied with $10 \%$ and $50 \%$ power difference between channels. Under $10 \%$ power difference (Figure 7(a)), the flow oscillation in Channel-2 is out-ofphase with Channel-1; however, the trend of the flashing pulses in both the channels is identical. In case of $50 \%$ power difference, the flow oscillation in Channel-2 is out-of-phase with Channel-1, with the first flashing pulse lagging behind 


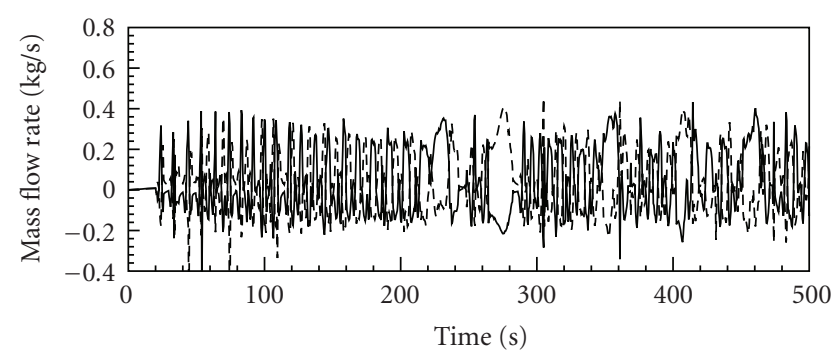

(a)

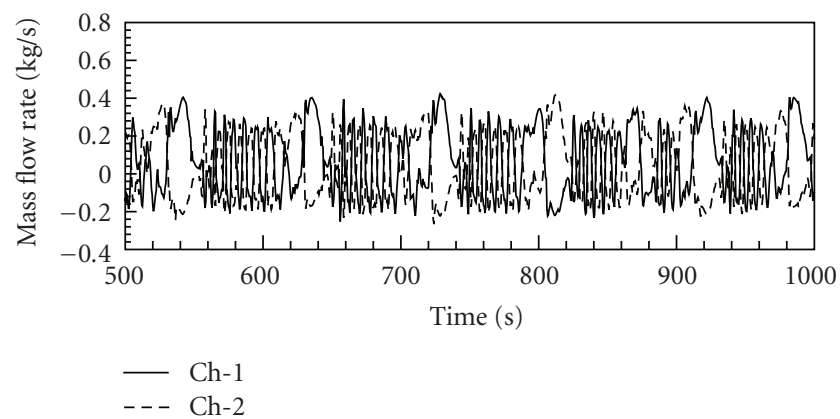

(b)

Figure 5: Core inlet flow rate for $10 \%$ power difference between channels in model.

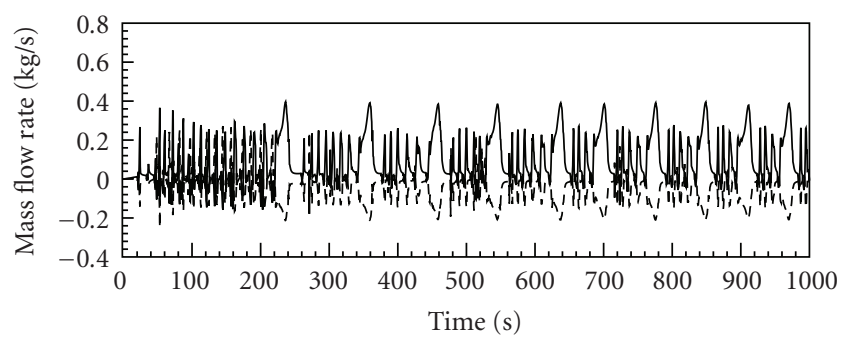

(a)

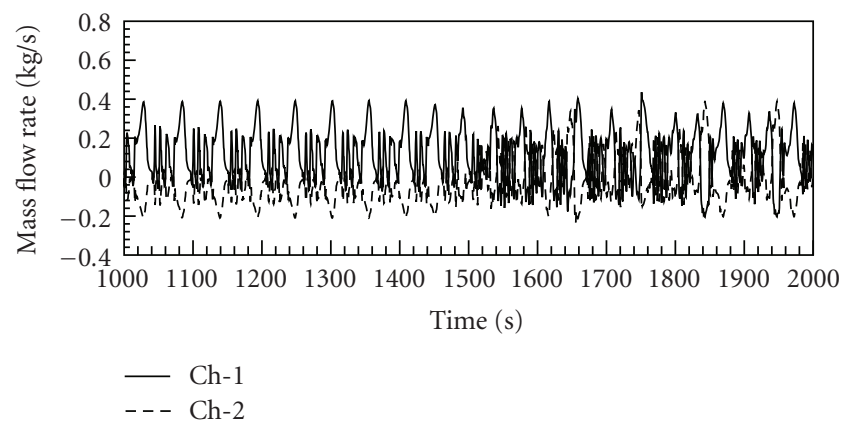

(b)

FIGURE 6: Core inlet flow rate for $50 \%$ power difference between channels in model.

approximately $400 \mathrm{~s}$, and the lag continues to increase with time for subsequent peaks. The trend of the flashing pulses in both channels is not identical either (Figure 7(b)). Channel2 experiences flow in reverse direction even at a stable flow condition during the initial stage of startup. This is due to lack of vapor generation owing to a relatively very low power

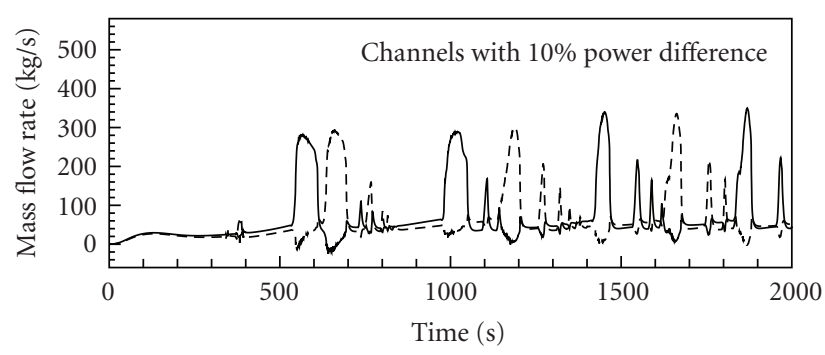

(a)

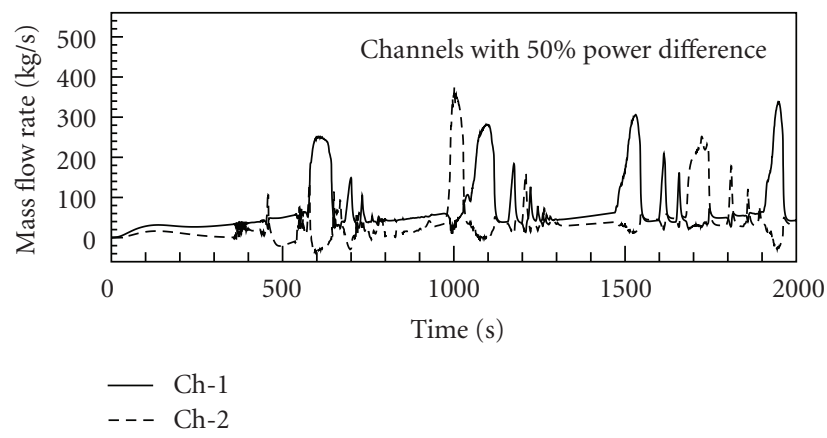

(b)

FIGURE 7: Core inlet flow rate for $10 \%$ and $50 \%$ power difference between channels in NCBWR.

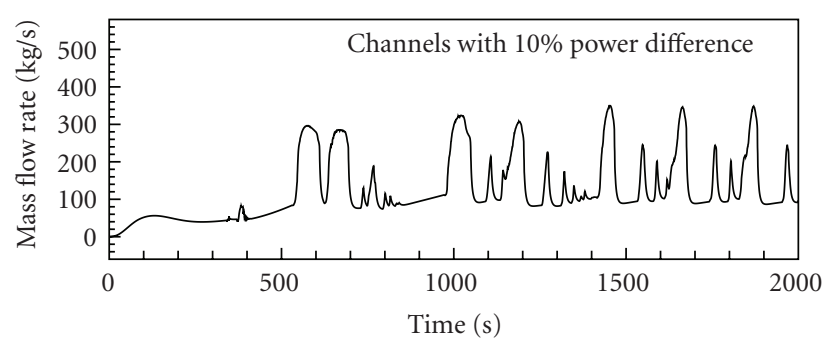

(a)

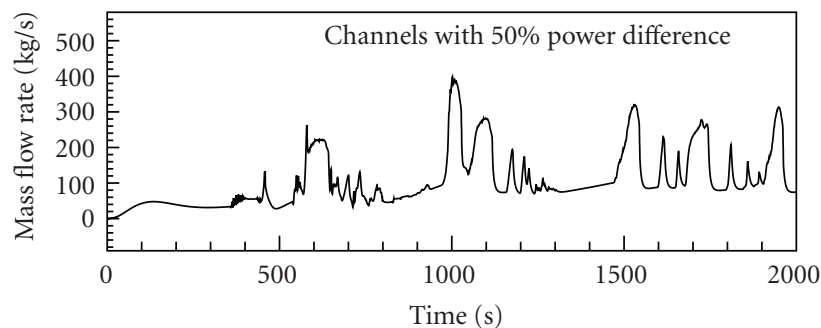

(b)

Figure 8: Downcomer flow rate for $10 \%$ and $50 \%$ power difference between channels in NCBWR.

supplied to Channel-2. In common, both the cases (10\% and $50 \%$ difference) show intermittent flow reversal, which is not observed under equal power condition. Flow reversal in this context refers to change in flow direction in one channel when there is a sudden surge in flow in the other channel due to flashing. The flow oscillations in the downcomer section are as shown in Figure 8. Due to out-of-phase character of the flashing pulses in the channels, the number of flow pulses 


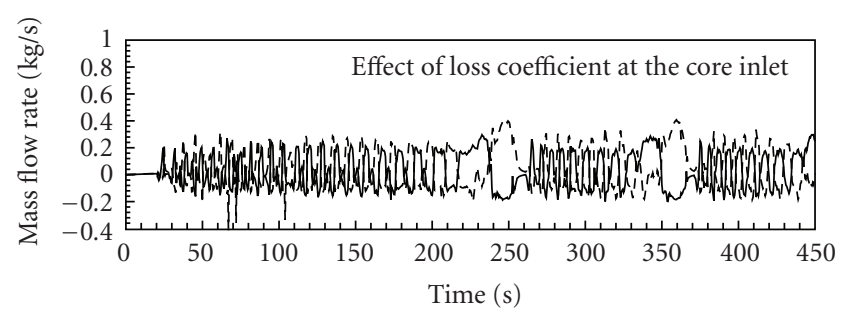

(a)

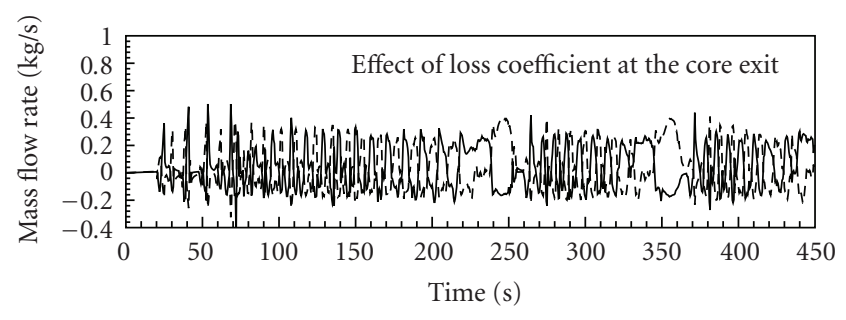

(b)

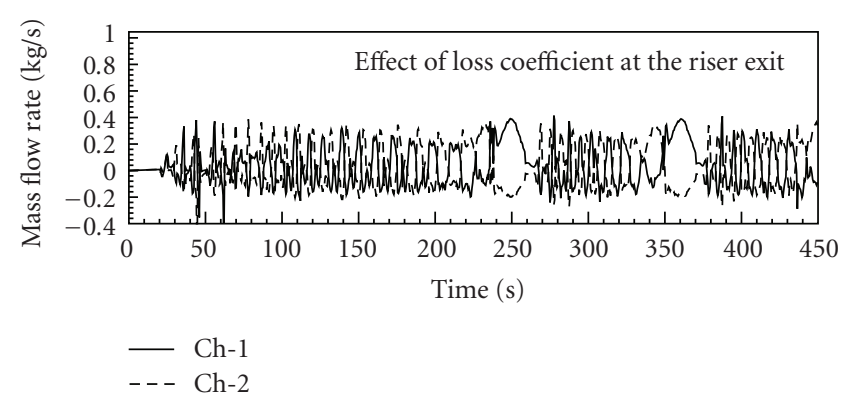

(c)

FIGURE 9: Effect of loss coefficient on startup oscillations in doublechannel model.

in the downcomer is doubled when compared to equal power condition where the flow is in-phase.

4.3. Effect of Loss Coefficients. Analysis was performed with different values of flow resistance (inlet and outlet) and has been reported as part of earlier publication [8], but for a single-channel study. In the present study, the effect of flow resistance on Type-I oscillation is explored by starting the system with the two channels having different flow restrictions, introduced at core inlet, core exit/riser inlet, and riser exit of the channels. For the simulation, the flow resistance is increased in only one channel (Channel-1), leaving the other channel with normal loss coefficient values. The effect of flow resistance and the effect due to unequal resistances in the channels are presented in Figure 9 (model) and Figure 10 (NCBWR).

The flow instability observed in the model is a result of void generation in both core and riser sections, as reported earlier [17]. It was found that the instability caused by core void generation is signified by low-amplitude highfrequency oscillations, and the riser void generation (flashing) results in high-amplitude low-frequency oscillation. Hence, flow resistance applied at different sections would

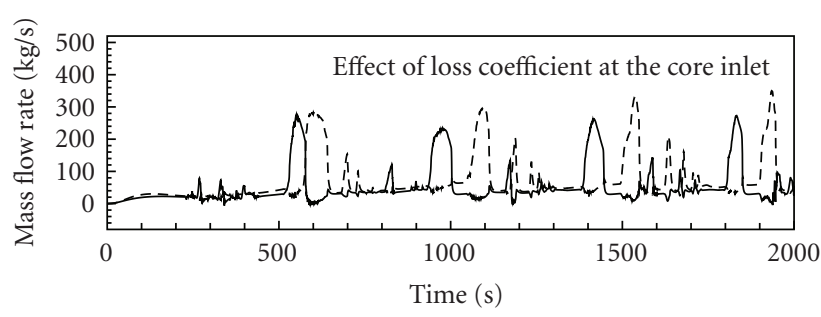

(a)

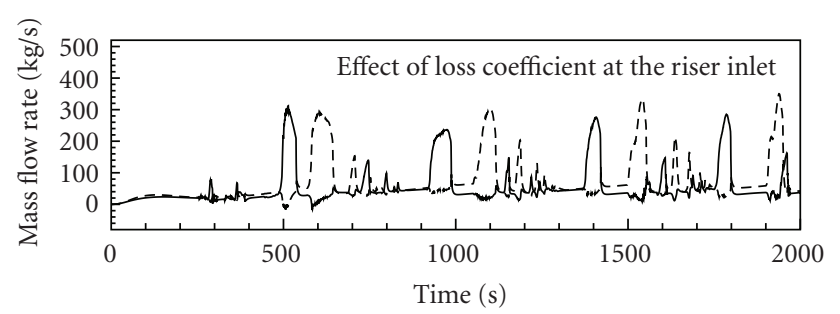

(b)

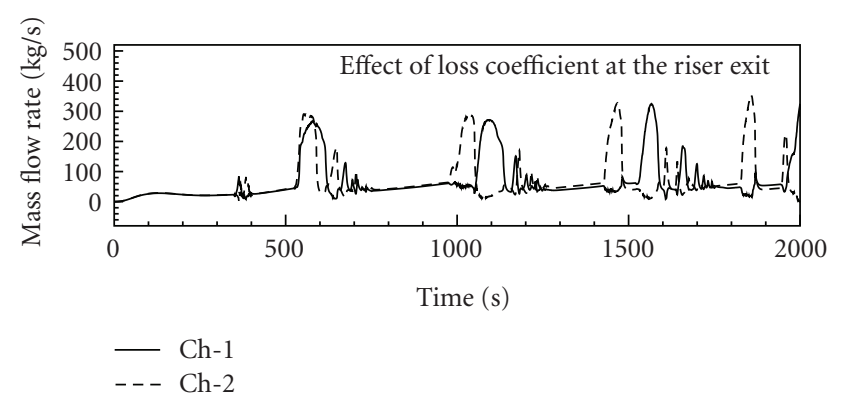

(c)

FIGURE 10: Effect of loss coefficient on startup oscillations in double-channel NCBWR.

have a corresponding effect on the instability arising from the respective section of the channel. Figure 9(a) shows the effect of inlet resistance on the flow in Channel-1. It can be seen that the amplitude of Channel-1 oscillation is reduced comparatively and the effect is only on the low-amplitude high-frequency oscillations as it is a core phenomenon. Additional flow resistance at the core exit is found to have a destabilizing effect on the system resulting in an increase in amplitude of oscillations in Channel-1 (Figure 9(b)). It is known from the literature [18] that, in general, inlet resistance has a stabilizing effect, and outlet resistance destabilizes the system. In case of riser exit resistance, it is expected to destabilize the system by influencing the flashing instability which is a riser phenomenon. This effect can be seen in Figure 9(c), as there is repeated appearance of highamplitude flashing pulse in Channel-1 due to the additional resistance to flow at the riser exit. A similar stabilizing and destabilizing effect of flow resistance on the flow oscillations was reported even for different values of loss coefficient [8].

In the NCBWR simulations, it is relatively straightforward to analyze the effect of loss coefficients, as the instability is only due to flashing in the riser, and there is no core void generation. It is inferred from Figure 10(a) that 
the amplitude of flow oscillations in Channel-1 is considerably reduced compared to Channel-2, due to the presence of additional loss coefficient at Channel-1 core inlet. When the loss coefficient is in place at the riser inlet (Figure 10(b)), there is a similar effect on the amplitude of oscillations it and only differs in the context of time lag between flashing pulse. In general perception, the riser inlet resistance can be taken as core exit resistance which has a destabilizing effect on the system. However, in this case, vapor generation (flashing) is predicted only in the riser section and hence the resistance at the core outlet acts as an inlet resistance to riser section, resulting in reduction of the amplitude of flow oscillation. In case of an increased resistance at the exit of the riser, there is no significant difference in the amplitude of the pulses but the trend of phase lag, that is, flashing in channel2 precedes channel-1 (Figure 10(c)) unlike the effect seen under core inlet and riser inlet restriction. Thus, the presence of additional loss coefficient in one channel results in out-ofphase flow oscillation in a parallel-channel NCBWR.

\section{Summary and Conclusions}

Numerical models of parallel-channel pressure tube type natural circulation boiling water systems have been developed using RELAP5/MOD3.4. Simulations have been done to predict the startup flow transients in parallel-channel systems with difference in power and flow restriction between channels.

(i) For identical startup conditions in channels, it is inferred that the nature of flow oscillation predicted in scaled model and the prototype is not similar, in the context of in-phase and out-of-phase behaviour. In the prototype model, the flow behavior in both the channels is characterized by flashing pulses which are in-phase. Whereas in the scaled model, even for identical conditions, there exists a phase difference between flow oscillations in channels.

(ii) Under non-identical conditions in channels, the simulations for both model and the prototype show similar trend, that is, the flow oscillations in the channels are out-of-phase.

(iii) In condition like difference in channel power, flow reversal is predicted in one channel when there is a sudden surge in flow due to flashing in the other channel.

(iv) The amplitude of flow oscillations is considerably reduced due to the presence of additional loss coefficient at the core and riser inlet. Presence of additional loss coefficient in one channel results in out-of-phase flow oscillation in a parallel-channel NCBWR.

In-phase oscillations would lead to high amplitude flow pluses in the downcomer as the flow in the downcomer is the sum of the flow in the parallel channels, and the time period would be equal to that of a flashing pulse. In case of out-of-phase oscillation the frequency of downcomer flow oscillations will be higher but the amplitude will be lower. It would be desirable to investigate the effect of in-phase and out-of-phase oscillations on flow-induced vibrations and material fatigue.

\section{Acknowledgment}

The authors duly acknowledge Atomic Energy Regulatory Board (AERB) for the financial support through a project being executed at IIT Guwahati.

\section{References}

[1] M. Aritomi, J. H. Chiang, and M. Mori, "Geysering in parallel boiling channels," Nuclear Engineering and Design, vol. 141, no. 1-2, pp. 111-121, 1993.

[2] C. Y. Wu, S. B. Wang, and C. Pan, "Chaotic oscillations in a low pressure two-phase natural circulation loop under low power and high inlet subcooling conditions," Nuclear Engineering and Design, vol. 162, no. 2-3, pp. 223-232, 1996.

[3] A. Manera and T. H. J. J. van der Hagen, "Stability of naturalcirculation-cooled boiling water reactors during startup: experimental results," Nuclear Technology, vol. 143, no. 1, pp. 77-88, 2003

[4] M. Furuya, F. Inada, and T. H. J. J. van der Hagen, "Flashinginduced density wave oscillations in a natural circulation BWR - mechanism of instability and stability map," Nuclear Engineering and Design, vol. 235, no. 15, pp. 1557-1569, 2005.

[5] M. H. Subki, M. Aritomi, N. Watanabe, H. Kikura, and T. Iwamura, "Transport mechanism of thermohydraulic instability in natural circulation boiling water reactors during startup," Journal of Nuclear Science and Technology, vol. 40, no. 11, pp. 918-931, 2003.

[6] C. Pan, S. B. Wang, C. C. Hsieh, et al., "Using a natural circulation loop to investigate the relevant thermal hydraulic phenomena in an ABWR,” TPC Project Report, 1999.

[7] J. D. Lee and C. Pan, "Nonlinear analysis for a double-channel two-phase natural circulation loop under low-pressure conditions," Annals of Nuclear Energy, vol. 32, no. 3, pp. 299-329, 2005.

[8] S. P. Lakshmanan, M. Pandey, P. Pradeep Kumar, and K. N. Iyer, "Study of startup transients and power ramping of natural circulation boiling systems," Nuclear Engineering and Design, vol. 239, pp. 1076-1083, 2009.

[9] H. S. Cheng, H. J. Khan, and U. S. Rohatgi, "Simulation of SBWR startup transients and stability,” Tech. Rep. BNL-65535, Brookhaven National Laboratory, 1998.

[10] Y.-M. Ferng and C.-H. Lee, "Numerical simulation of natural circulation experiments conducted at the IIST facility," Nuclear Engineering and Design, vol. 148, no. 1, pp. 119-128, 1994.

[11] S. P. Lakshmanan, M. Pandey, P. P. Kumar, and K. N. Iyer, "Simulation for startup transients in a natural circulation boiling loop," in Proceedings of the 16th International Conference on Nuclear Engineering (ICONE '08), vol. 3, pp. 397-402, Orlando, Fla, USA, May 2008.

[12] C. M. Allison and J. K. Hohorst, "Role of RELAP/SCDAPSIM in nuclear safety," Science and Technology of Nuclear Installations, vol. 2010, Article ID 425658, 17 pages, 2010. 
[13] R. K. Sinha and A. Kakodkar, "Design and development of the AHWR-the Indian thorium fuelled innovative nuclear reactor," Nuclear Engineering and Design, vol. 236, no. 7-8, pp. 683-700, 2006.

[14] K. N. Iyer and A. Kadengal, "Scaling of natural circulation boiling systems," in Proceedings of ASME Heat Transfer Conference (HT '03), pp. 715-720, Las Vegas, Nev, USA, July 2003.

[15] W. L. Chen, S. B. Wang, C. R. Chung, S. S. Twu, and C. Pan, "Two-phase flow instability in a double-channel natural circulation loop with equal or unequal heating powers," in Proceedings of International Conference on Nuclear Engineering (ICONE '99), Tokyo, Japan, 1999.

[16] V. Jain, A. K. Nayak, P. K. Vijayan, D. Saha, and R. K. Sinha, "Experimental investigation on the flow instability behaviour of a multi-channel boiling natural circulation loop at low-pressures," in Proceedings of International Topical Meeting on Nuclear Reactor Thermal Hydraulics (NURETH '99), Kanazawa, Japan, 2009.

[17] S. P. Lakshmanan and M. Pandey, "Analysis of startup oscillations in natural circulation boiling systems," Nuclear Engineering and Design, vol. 239, no. 11, pp. 2391-2398, 2009.

[18] G. V. Durga Prasad, M. Pandey, and M. S. Kalra, "Review of research on flow instabilities in natural circulation boiling systems," Progress in Nuclear Energy, vol. 49, no. 6, pp. 429451, 2007. 

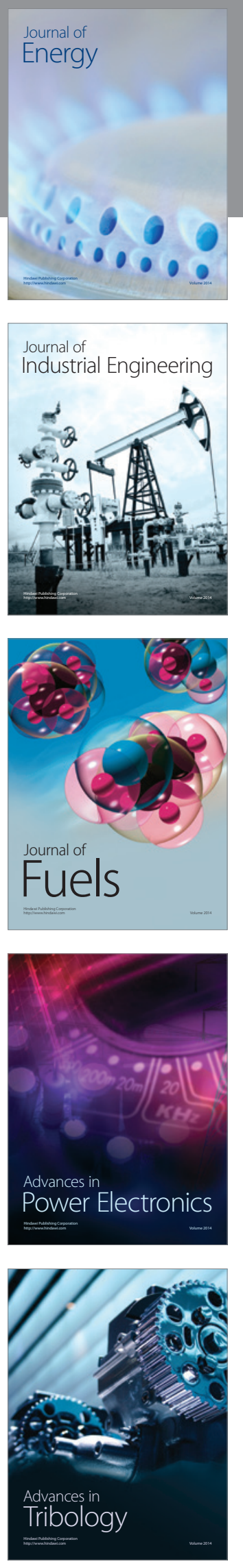
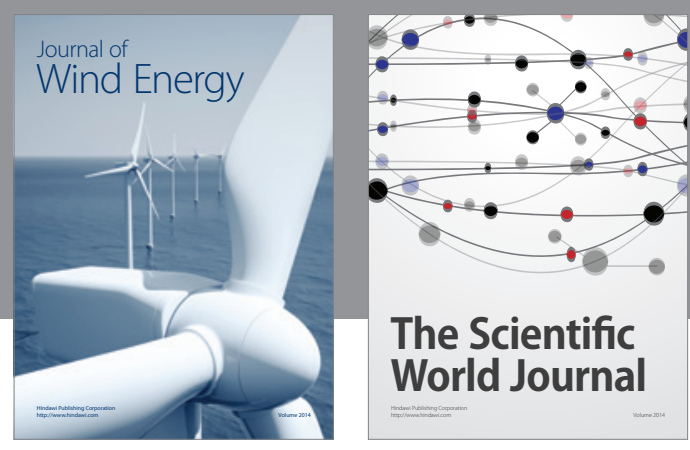

The Scientific World Journal

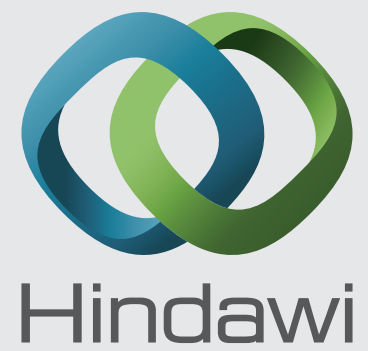

Submit your manuscripts at http://www.hindawi.com
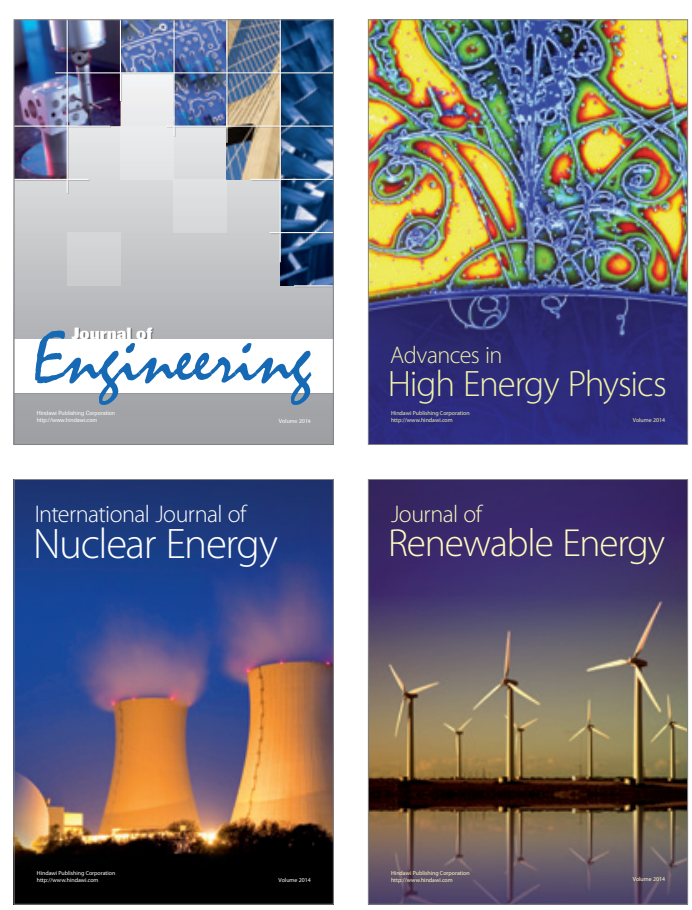

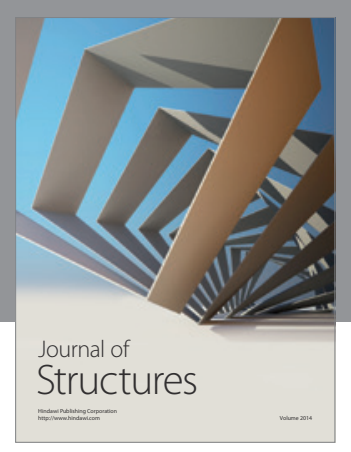

Rotating
Mechinery
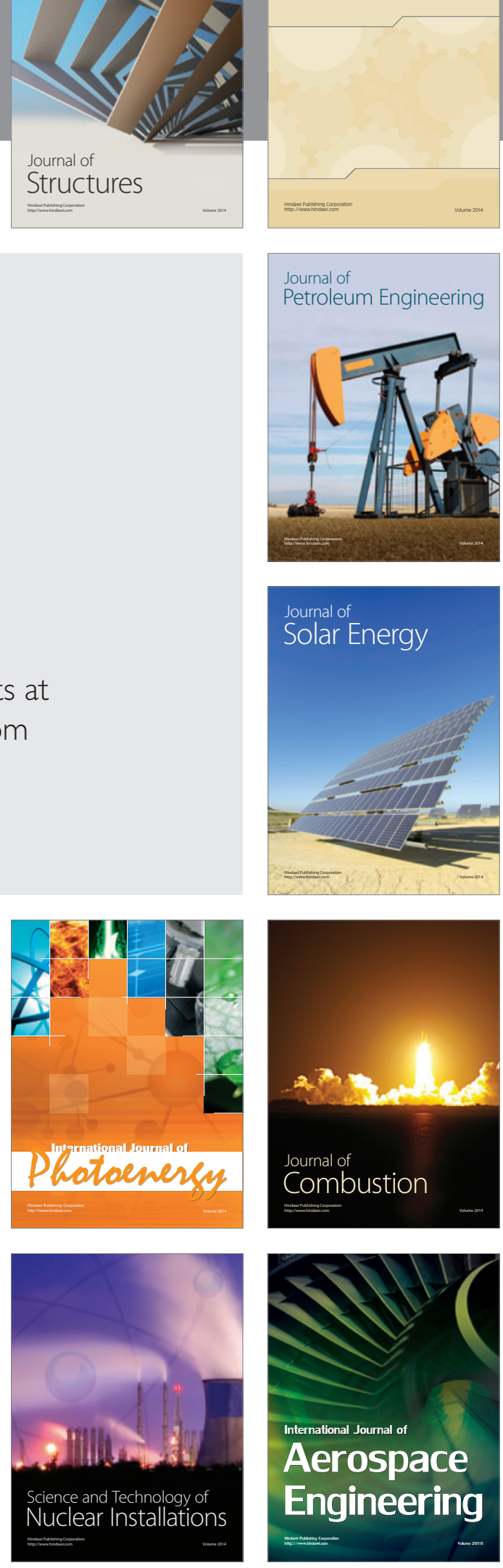